\title{
Can Small Business in Retailing Afford Digital Media Data Analytics?
}

\author{
Sookhyun Kim* \\ Management \& Marketing, East Tennessee State University, USA
}

*Corresponding author: Sookhyun Kim, Management \& Marketing, College of Business and Technology, East Tennessee State University, Johnson City, Tennessee, USA.

Received Date: July 10, 2020

Published Date: July 23, 2020

\begin{abstract}
Due to the COVID 19 pandemic this year, many offline retailers of all sizes have closed or converted to online retail to survive. Online retailing through digital media have become a major focus of retail businesses today. Consumer data is no longer coming from Point-of-Sales (POS) systems in offline stores but is from data stored in digital media such as website and social media systems. Data-driven marketing decision-making is essential today. However, many small businesses have limited budgets and lack human resources equipped with adequate data skills to effectively utilize the data. Therefore, the researcher recommends utilizing open-source software programs (OSS), which are free to the public, and it was proven that OSS provided valuable insights into customer data, and the marketing strategy based on OSS data analysis successfully improved business performance. In addition, government's support could further help small business learn data analytics and make data-driven marking decisions, which ultimately would lead to the continuing success and/or survival of small business.
\end{abstract}

Keywords: Business analytics; Data analytics; Digital media; Key performance indicators; Small business; Open-source software

\section{Introduction}

Due to the COVID 19 pandemic this year, many offline retailers of all sizes have closed or converted to online retail to survive. Online retailing through digital media (i.e., electronic-commerce, mobile-commerce, and social-commerce) have become a major focus of retail businesses today. As a result of the growing closures of offline retailers due to health/safety concerns, consumers have been forced into using digital media for shopping. Consumers shopping behavior had rapidly been changing to use online retailers even before the pandemic, but the pandemic accelerated this change in consumer behavior. For this reason, utilizing digital media for sales and marketing has become an imperative for businesses. According to Hasselman T [1] 72\% of participating businesses increased return on investment (ROI), and nearly half of participants observed a 300\% increase in revenue after using digital media for their business.
Consumer data is no longer coming from Point-of-Sales (POS) systems in offline stores but is from data stored in digital media such as website and social media systems. Businesses have incorporated digital media into their business practices and are trying to develop effective communication and product/service strategies based on their customer data. Large corporations can afford data scientists and data/marketing analysts, who execute complicated data analysis with various data analytics techniques and interpret the results to create appropriate marketing strategies. However, many small businesses have limited budgets, lack human resources equipped with adequate data skills to effectively utilize the data, and often perceive digital media marketing as being a timeconsuming and complex practice. As a result, small businesses use digital media as a platform only to push their products and services (i.e., push marketing), not to pull customer data from the systems to predict customer demand and market products and services 
according to customer expectations (i.e., pull marketing through business analytics process).

\section{Discussion}

Business analytics includes descriptive analytics, predictive analytics, and prescriptive analytics [2]. Analysts comb through the data to discover past facts of a business (i.e., descriptive analytics) and to predict future trends of a business from the past facts (i.e., predictive analytics). Various data analytics techniques are used in these analytics types such as Crawling, Social Network Analysis, Topic Modeling, Text Classifier, Opinion Mining, Sentiment Analysis Trend analysis, Clustering, Cascading link, Visual Analytics, etc. [3]. Finally, marketing analysts interpret the results of the analysis to create appropriate marketing strategies (i.e., prescriptive analytics) to improve business performance. The researcher claims that descriptive and predictive analytics can be executed by computer programs, but prescriptive analytics can be run only by human analysts due to interrelationship between business specific internal/external environments and businesses' key performance indicators (KPIs) from the analysis, which software programs cannot consider all at the same time.

Data-driven marketing decision-making is essential today. The issue is that many small businesses cannot afford data and marketing analysts. Therefore, the researcher recommends utilizing opensource software programs (OSS), which are free to the public, and Small Business Administration (SBA) offices offer various seminars to teach OSS free of charge, or with an affordable fee for small businesses. OSS replace the role of data analysts and help small businesses extract marketing insights from the data. For example, Google Analytics program can analyze a business's website data and social media data with various analytics techniques. Google Tag Manager enables data to be imported from various digital media platforms into Google Analytics. Facebook Insights or Instagram Insights offer data analytics for its own social media platform users. These OSS could present descriptive and predictive data analysis; however, they cannot generate appropriate marketing strategies, which needs human analysts' interpretation of data analysis based on the businesses' environments. Therefore, Kim S [4] proposed a map of how to interpret the data analysis results from OSS with KPIs and how to create marketing strategies based on the results. After creating the marketing strategies, businesses need to implement the strategies. For example, businesses could invest in Google Ads and Facebook Ads to reach out more and target customers in different locations. Afterwards, Google Optimize program is available to measure the success of the marketing strategy before and after implementation, so called A/B testing. Free classes to learn Google Analytics, Google Tag Manager, and Google Optimize are available at Google Analytics Academy. Kim S, et al. [3] case study proved that OSS provided valuable insights into customer data, and the marketing strategy based on OSS data analysis successfully improved business performance.

\section{Conclusion}

Digital media systems store useful data for businesses to accurately predict customers' demand on products and services. The importance and the urgency of utilizing data analytics is well presented in Sztandera's article in the Journal of Textile Science and Fashion Technology (2020) [5]. Small businesses occupy 99.7\% of US businesses and are encountering a challenge to survive in this unexpected business environment [6]. Many textile and apparel businesses are small businesses, which cannot afford data analysts; therefore, OSS could be very helpful tools for them to look inside their customer data. In addition, government's support could further help small business learn data analytics and make data-driven marking decisions, which ultimately would lead to the continuing success and/or survival of small business. History provides us many examples of government support allowing endangered businesses to survive bad economic circumstances and return to economic prosperity after the adverse circumstances withered away [7]. The textile and apparel industry have been historically protected and supported by the governments of many countries because this industry was essential to economic development. It is the time to support and protect small businesses more because they represent the backbone of the US economy today.

\section{Acknowledgement}

None.

\section{Conflict of Interest}

None.

\section{References}

1. Hasselman T (2016) Social Media Marketing Sees Massive ROI Growth. Salesforce.

2. (2019) "Types of Analytics: descriptive, predictive, prescriptive analytics." ProjectPro, DeZyre.

3. Kim S, Atkinson K (2020) Is Open-Source Data Analytics Software Viable for Small businesses? A Case Study of Google Analytics and Google Optimize as Substitutes of Data Scientists. American Marketing Association Summer Academic Conference, San Francisco, USA.

4. Kim S (2020) Mapping Social Media Analytics for Small Business: A Case Study of Business Analytics. American Marketing Association Summer Academic Conference, San Francisco, USA.

5. Sztandera L (2020) Thoughts on the future of data analytics education in college fashion curricula. Journal of Textile Science and Fashion Technology 6(1): 1-3.

6. SBA Office of Advocacy (2016) United States Small Business Profile.

7. Kim S, Ko E (2014) Analysis of Global Fashion Cities: Focus on Fashion Policies and Value Contributions. 2014 Global Fashion Management Conference, Global Alliance of Marketing \& Management Associations, London, UK. 